\title{
Pengaturan Kecepatan Pada Motor Brushless DC (BLDC) Menggunakan PWM (Pulse Width Modulation)
}

\author{
1Danu Akbar \& 2Slamet Riyadi \\ Teknik Elektro, Fakultas Teknik, Universitas Katolik Soegijapranata \\ Semarang, Indonesia
}

danuakbar99@yahoo.co.id, sriyadi7167@gmail.com

\begin{abstract}
Abstrak
Perkembangan teknologi dalam bidang trasportasi berkembang cukup pesat khususnya pada kendaraan listrik, hal ini didasari oleh krisis bahan bakar fosil. Salah satu penggerak yang banyak digunakan di dalam kendaraan listrik adalah motor brushless $D C$ (BLDC) di karenakan motor BLDC memiliki kelebihan yaitu torka yang tinggi serta pengaturan kecepatanya mudah. Beberapa penelitian terkait motor BLDC telah dilakukan oleh para ahli diantaranya adalah pengaturan kecepatan BLDC, pembebanan pada motor BLDC serta lainya. Pada makalah akan dikaji tentang pengaturan kecepatan motor Brushless DC dengan menggunakan PWM (Pulse Width Modulation), metode PWM pada prisipnya adalah mengatur duty cycle yang dihasilkan oleh mikrokontroler untuk pensaklaran pada Inverter Tiga Fasa. Semakin besar duty cycle maka kecepatan motor BLDC tersebut juga akan semakin tinggi dan sebaliknya. Untuk mendukung analisis maka dilakukan pengujian laboratorium.
\end{abstract}

Kata kunci : brushless dc, inverter tiga fasa, PWM (Pulse Width Modulation), mikrokontroller, duty cycle

\section{Pendahuluan}

Perkembangan teknologi saat ini berkembang sangat pesat dan berbagai inovasi baru mulai bermunculan, di antaranya dalam bidang perindustrian, pertambangan maupun transportasi. Semakin berkembangnya teknologi membuat mesin listrik semakin berkembang sesuai kebutuhanya. Mesin listrik merupakan salah satu alat yang sangat penting perannya dalam kehidupan sehari hari, tak terkecuali pada bidang transportasi kendaraan yang ramah lingkungan menjadi salah satu tren di mata produsen alat transportasi, hal ini dipicu oleh isu global warming yang dihasilkan oleh alat tranpotasi yang masih menggunakan mesin bakar. Untuk mengatasi masalah tersebut produsen alat trasportasi sekarang mulai merubah mesin penggerak utama pada alat transportasinya dengan cara meggunakan mesin listrik,dimana yang sebelumnya menggunakan mesin bakar. Oleh karena itu Motor BLDC menjadi salah satu pilihan alternative dikarenakan motor BLDC memiliki beberapa keunggulan dibandingkan motor DC konvensional yang masih menggunakan brush dan komutator sedangkan motor BLDC tidak menggunakan brush dan komutator melainkan menggunakan rangkaian elektronika sebagai kendali motor BLDC tersebut. Kelebihan motor BLDC dibandingkan motor DC konvensional yaitu, efisiensi tinggi, masa operasi lebih tinggi, perawatan yang rendah, serta tingkat kebisingan yang rendah karena putarannya halus.

Pada makalah ini akan membahas tentang pengontrolan serta pengaturan kecepatan motor BLDC yang dapat diaplikasikan pada alat transportasi. Sistem kendali motor BLDC ini menggunakan Inverter 3 fasa sebagai pensaklaran suatu motor BLDC yang dikendalikan secara digital oleh mikrokontrol, serta dijalankan menggunakan sinyal PWM dengan duty cycle variabel yang dihasilkan oleh mikrokontroler sebagai pengatur kecepatan pada motor BLDC.

\section{Metodologi Penelitian}

Pada makalah ini penulis akan membahas tentang kendali pengaturang kecepatan pada motor brushlees DC menggunakan sinyal PWM pulse width dengan duty cycle variabel yang dikueluarkan oleh mikrokontroler.

\subsection{Motor Brushless DC (BLDC)}

Pada dasarnya motor BLDC bekerja dengan menggunakan prinsip gaya tarik antara dua magnet yang berlainan kutub atau gaya tolak antara dua magnet dengan kutub yang sama. Rotor pada motor BLDC tersusun dari magnet permanen sehingga kutubnya tetap sedangkan stator terbuat dari belitan sehingga kutub magnet tersebut dapat berubah tergantung polaritas arus belitan stator yang diberikan. Di bawah ini akan dijelaskan tentang kontruksi pada motor BLDC. 


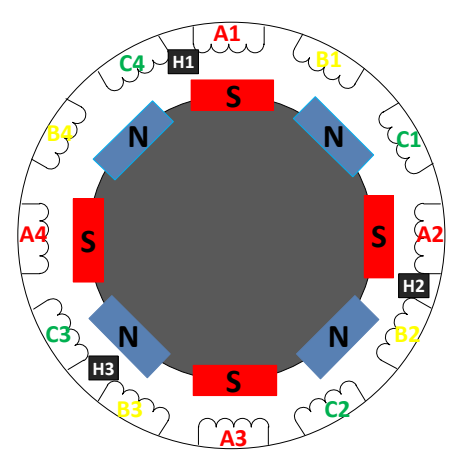

Gambar 1 Kontruksi motor brushless DC

Pada gambar 1 disajikan motor BLDC dengan 12 belitan stator dan 8 kutub magnet pada rotor. Untuk memutar motor BLDC harus mengetahui posisi rotor yang terletak di dalam motor BLDC digunakan untuk mengontrol belitan pada stator yang mana akan diberi tegangan sesuai polaritasnya untuk menarik atau mendorong magnet pada rotor sehingga rotor dapat bergerak atau berputar. Untuk mendeteksi posisi rotor dapat menggunakan Hall effect sensor yang ditempelkan pada stator. Di dalamn motor BLDC memiliki tiga hall effect sensor yang dipasang di stator. Tiga buah hall effect sensor diletakan pada posisi sebagai berikut : $\mathrm{H} 1$ pada posisi $\theta=360^{\circ}, \mathrm{H} 2$ pada posisi $\theta=60^{\circ}$, H3 pada posisi $\theta=120^{\circ}$ terhadap stator. sensor hall effect memberikan keluaran berlogika "1" saat mendeteksi kutub magnet utara $(\mathrm{N})$ dan berlogika "O" saat mendetaksi kutub magnet selatan (S). Dapat kita liat pada gambar 2 di bawah ini

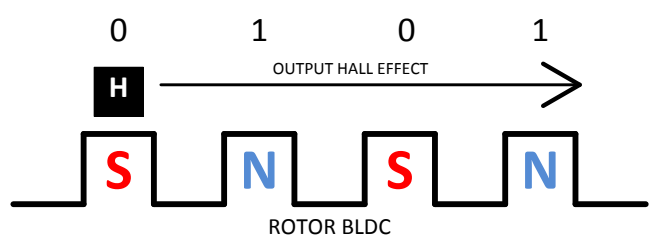

Gambar 2 pembacaan dari hall effect

\section{Tabel 1 data pembacaan hall effect 6 langkah}

\begin{tabular}{|c|c|c|c|c|c|}
\hline H1 & H2 & H3 & Van & Vbn & Vcn \\
\hline $\mathrm{O}$ & $\mathrm{O}$ & 1 & - & + & $\mathrm{O}$ \\
\hline 1 & $\mathrm{O}$ & 1 & $\mathrm{O}$ & + & - \\
\hline 1 & 0 & $\mathrm{O}$ & + & $\mathrm{O}$ & - \\
\hline 1 & 1 & $\mathrm{O}$ & + & - & $\mathrm{O}$ \\
\hline $\mathrm{O}$ & 1 & $\mathrm{O}$ & $\mathrm{O}$ & - & + \\
\hline $\mathrm{O}$ & 1 & 1 & - & $\mathrm{O}$ & + \\
\hline
\end{tabular}

Tabel diatas adalah data pembacaan dari hall effect serta pemberian tegangan pada stator sesuai polaritasnya. Pada motor BLDC ini implementasinya menggunakan sumber DC sebagai sumber energi utama yang kemudian diubah menjadi tegangan AC dengan menggunakan inverter 3 fasa.

\subsection{Inverter Tiga Fasa}

Motor BLDC ini implementasinya menggunakan sumber DC sebagai sumber energi utama yang kemudian diubah menjadi tegangan $\mathrm{AC}$ dengan menggunakan inverter 3 fasa.

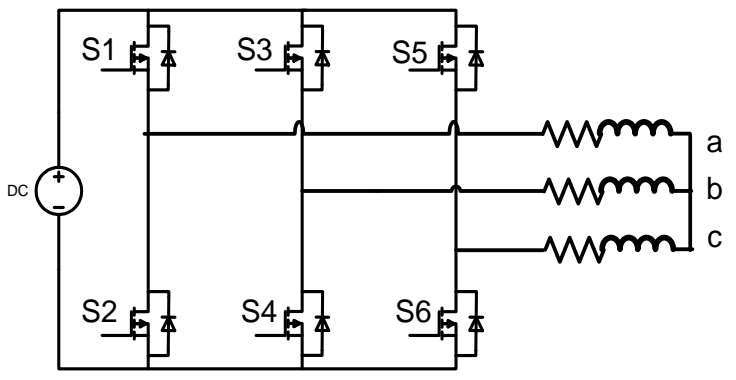

Gambar 3 rangkaian inverter 3 fasa

Tujuan dari pemberian tegangan AC 3 fasa pada stator BLDC adalah menciptakan medan magnet putar stator untuk menarik magnet rotor diperlukan pensaklaran suatu motor BLDC yang dikendalikan secara digital. Untuk memutar motor BLDC, belitan stator harus diberi tegangan dengan suatu urutan pensaklaran sesuai dengan operasi 6 langkah yang susuai dari pembacaan yang kami rancang. Seperti pada table dibawah ini :

Tabel 2 operasi 6 mode pensaklaran pada inverter 3 fasa

\begin{tabular}{|c|c|c|c|c|c|c|c|c|}
\hline S6 & S5 & S4 & s3 & S2 & S1 & Van & Vbn & Vcn \\
\hline 0 & 0 & 0 & 1 & 1 & 0 & $-V d c$ & Vdc & 0 \\
\hline 1 & 0 & 0 & 1 & 0 & 0 & 0 & Vdc & - Vdc \\
\hline 1 & 0 & 0 & 0 & 0 & 1 & Vdc & 0 & $-V d c$ \\
\hline 0 & 0 & 1 & 0 & 0 & 1 & Vdc & $-V d c$ & 0 \\
\hline 0 & 1 & 1 & 0 & 0 & 0 & 0 & $-V d c$ & Vdc \\
\hline 0 & 0 & 0 & 1 & 1 & 0 & $-V d c$ & 0 & Vdc \\
\hline
\end{tabular}

Dari tabel operasi 6 mode tersebut maka dihasilkan enam macam konfigurasi switching dari inverter 3 fasa tersebut. Sistem pensaklaran dapat dijelaskan pada mode operasi dibawah ini.

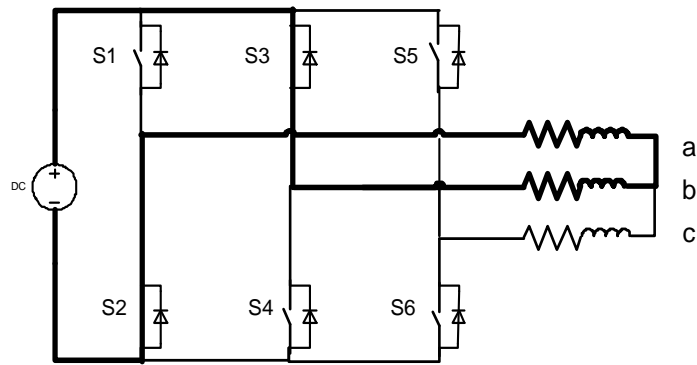

Gambar 4 mode 1 b-a (S3 on)dan (S2 on) 


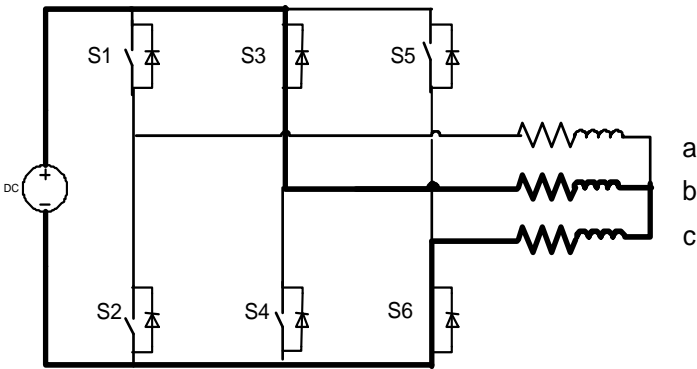

Gambar 5 mode 2 b-c (S3 on)dan (S6 on)

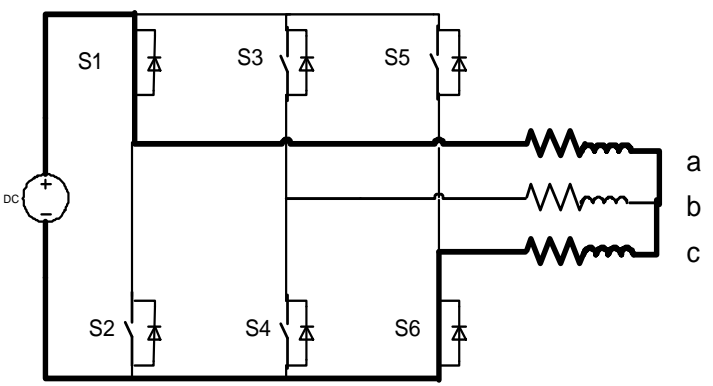

Gambar 6 mode 3 a-c (S1 on) dan (S6 on)

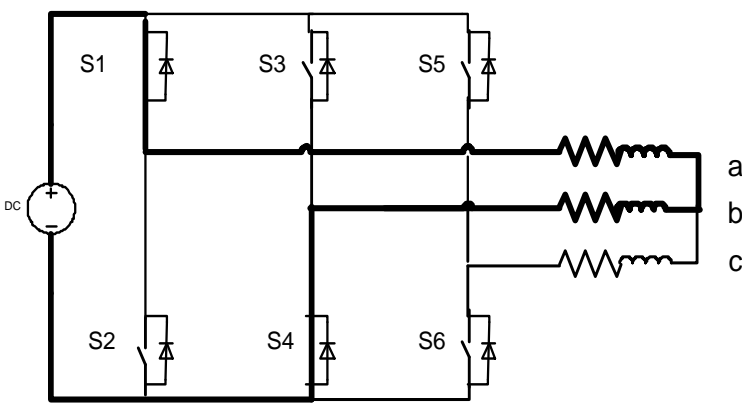

Gambar 7 mode 4 a-b (S1 on) dan (S4 on)

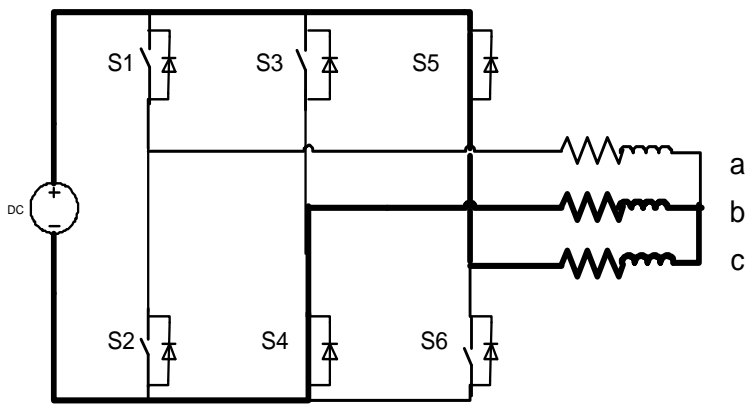

Gambar 8 mode 5 c-b (S5 on) dan (S4 on)

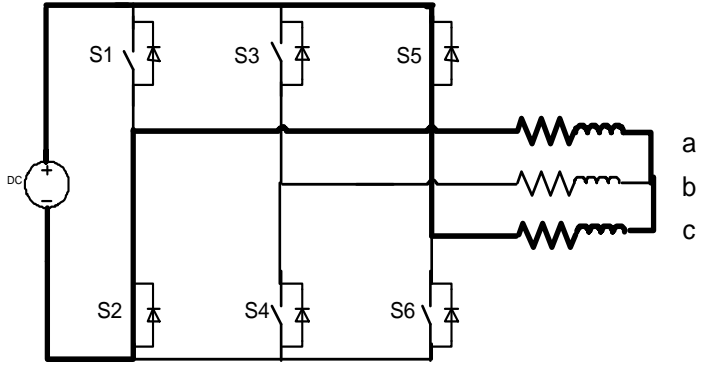

Gambar 9 mode 6 c-a (S5 on) dan (S2 on)

\subsection{Pulse Width Modulation (PWM)}

PWM merupakan suatu proses perbandingan antara sinyal carrier dengan sinyal modulasi sehingga menghasilkan sinyal kotak dengan lebar pulsa yang berbeda. Lebar pulsa tersebut dapat diatur dengan duty cycle. Duty cycle merupakan prosentase periode sinyal high dan periode sinyal low, presentase duty cycle akan berbanding lurus dengan tegangan rata rata yang dihasilkan. Sinyal PWM memiliki lebar pulsa yang bervariasi sesuai duty cycle. Di bawah ini gambar penjelasan sinyal PWM.

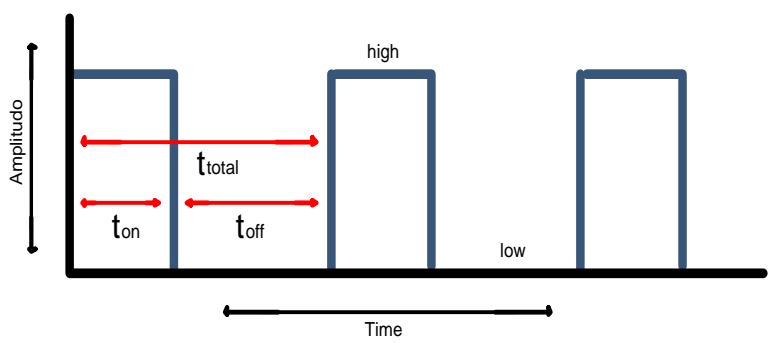

Gambar 10 sinyal pwm (pulse width modulation)

ton adalah waktu dimana tegangan keluaran berada pada posisi high atau berlogika 1. toff adalah waktu dimana tegangan keluaran berada pada posisi low atau berlogika 0 . $t_{\text {total }}$ adalah waktu satu siklus atau penjumlahan antara ton dengan toff, biasa dikenal dengan "periode satu gelombang".

$t_{\text {total }}=t_{o n}+t_{o f f}$

siklus kerja atau duty cycle sebuah gelombang didefenisikan sebagai,

$d=\frac{t_{\text {on }}}{(\text { ton }+ \text { toff })} \times 100 \%$

Tegangan keluaran dapat bervariasi dengan duty cycle dan dapat dirumuskan sebagai berikut,

$V_{\text {out }}=d \times V_{\text {in }}$ 


\subsection{Desain dan Implementasi}

Pada penelitian ini motor BLDC dijalankan menggunakan sinyal PWM dengan duty cycle variabel yang dihasilkan oleh mikrokontroler dsPIC30F4012 dengan topologi Inverter Tiga Fasa sebagai pensaklaran pada motor Brushless DC. Pembacaan pada posisi rotor dengan menggunakan sensor Hall Effect untuk mendeteksi letak magnet pada rotor. Sistem kontrol terdiri dari sebuah driver yang didalamnya terdapat dari IC optocoupler TLP250 dan Inverter 3 fasa menggunakan IGBT CPV364M4F , juga sebuah catu daya yang terdiri dari komponen B1212 dan B1205 yang menghasilkan keluaran $12 \mathrm{~V}$ dan $5 \mathrm{~V}$.

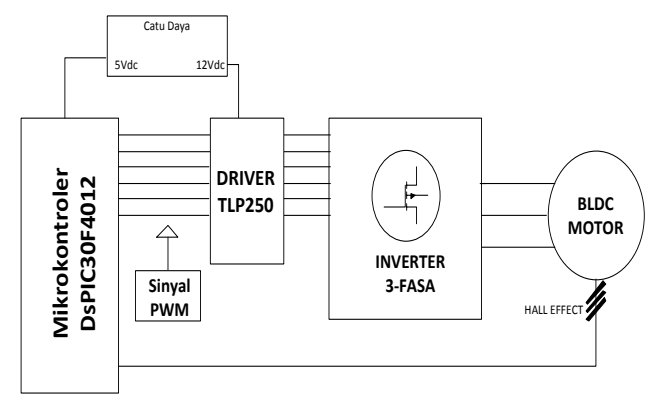

Gambar 11 diagram blok rangkaian konrol BLDC

Pengaturan kecepatan pada motor brushless dc dijalankan dalam kondisi motoring dengan sinyal PWM yang duty cycle diatur secara variabel menggunakan potensio sehingga kecepatan motor bldc dapat berubah ubah sesuai sinyal PWM tersebut.kemudian motor BLDC dijalankan untuk mengerakan generator dc. Di mana pada stator generator dc tersebut diberi beban sebesar $30 \Omega$.

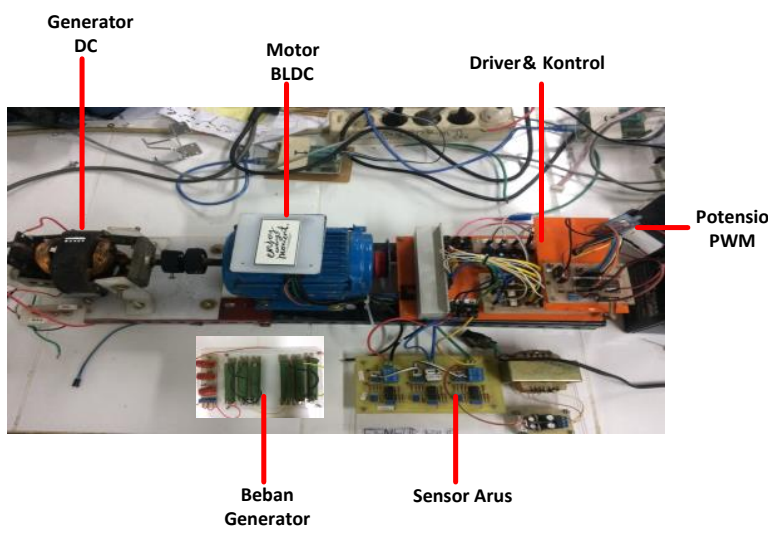

Gambar 12 foto prototype

\section{Hasil Pengujian}

Untuk mendukung analisis maka dilakukan pengujian prototipe. setelah melakukan pengujian prototipe selanjutnya dilakukan pengambilan data yang telah mendapatkan hasil. hasil yang diperoleh yaitu perbandingan antara PWM (Pulse Width Modulation) dengan duty cycle 75\% dan 50\% akan menghasilkan kecepatan yang berbeda. Ditampilkan pada tabel 3 di bawah ini.

Tabel 3 Data perbadingan antara duty cycle $75 \%$ dan duty cycle $50 \%$

\begin{tabular}{|c|c|c|c|}
\hline $\begin{array}{c}\text { Duty } \\
\text { Cycle }\end{array}$ & $\begin{array}{c}\text { Vout } \\
\text { Generator }\end{array}$ & $\begin{array}{c}\text { Beban } \\
\text { Generator }\end{array}$ & RPM \\
\hline $75 \%$ & $4,3 \mathrm{Vdc}$ & $30 \mathrm{Ohm}$ & 680 \\
\hline $50 \%$ & $2,5 \mathrm{Vdc}$ & $30 \mathrm{Ohm}$ & 398 \\
\hline
\end{tabular}

Di bawah ini hasil sinyal PWM yang diseting pada duty cycle $50 \%$ dan $75 \%$ yang dihasilkan oleh mikrokontrole sebelum motor BLDC berputar atau kondisi off. Pembacaan sinyal dengan osiloscope.

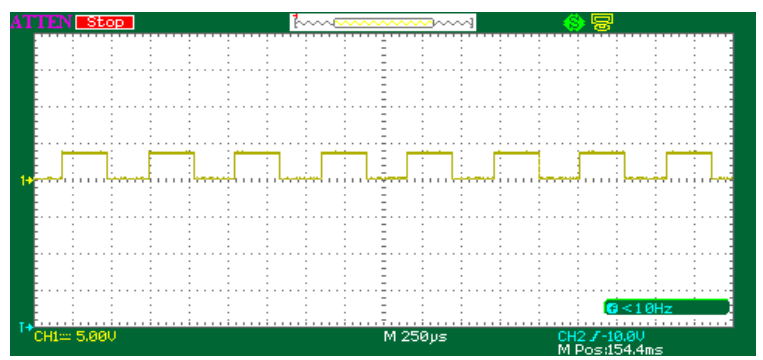

Gambar 13 gelombang PWM duty cycle 50\% pada output mikrokontroler

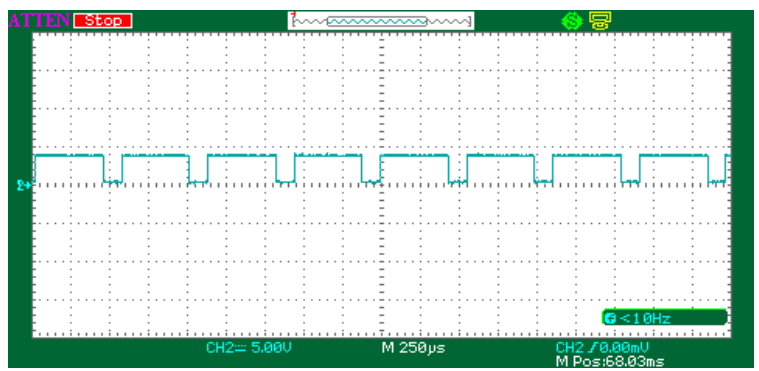

Gambar 14 gelombang PWM duty cycle $75 \%$ pada output mikrokontroler

Di bawah ini akan ditampilkan hasil pengujian pada motor BLDC dalam kondisi berputar atau motoring dengan duty cycle 50\% dan $75 \%$ sinyal PWM yang dihasilkan oleh mikrokontroler. Pembacaan sinyal Arus, Tegangan dan Antar Tegangan dengan osiloscope. 


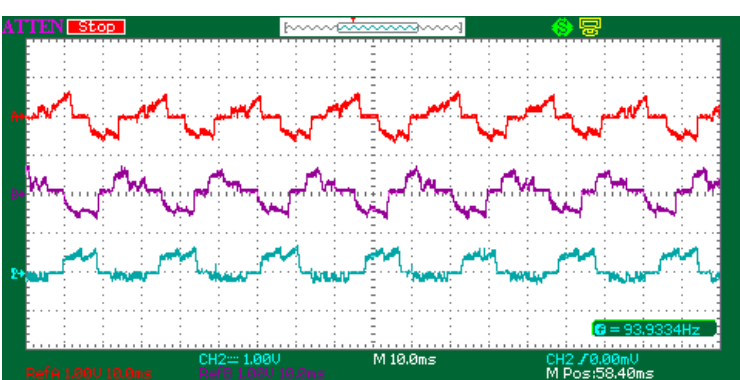

Gambar 15 gelombang arus (la, Ib, Ic) pada duty cycle $75 \%$

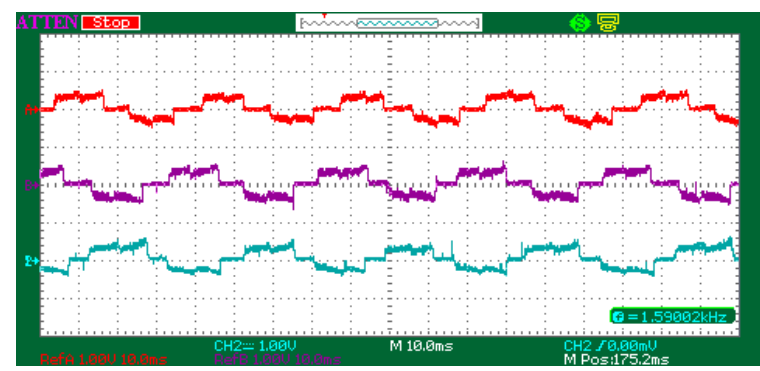

Gambar 16 gelombang arus (la, Ib, Ic) pada duty cycle $50 \%$

Dapat dilihat pada gambar 15 dan gambar 16 bahwa perbandingan sinyal arus (la,lb,lc) pada duty cylcle $50 \%$ bentuk sinyal arus lebih lebar daripada bentuk sinyal parus pada duty cycle $75 \%$.

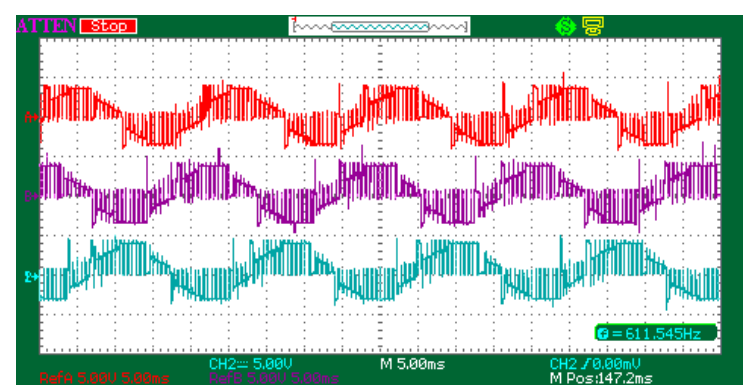

Gambar 17 gelombang tegangan antar fasa (Vab, Vbc, Vca) pada duty cycle $75 \%$

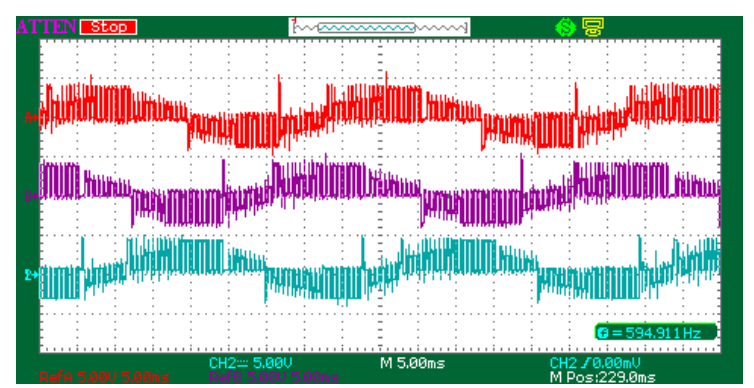

Gambar 18 gelombang tegangan antar fasa (vab, vbc, vca) pada duty cycle $50 \%$

Dapat dilihat pada gambar 17 dan gambar 18 bahwa perbandingan sinyal tegangan antar fasa (Vab,Vbc,Vca) pada duty cylcle 50\% bentuk sinyal arus lebih lebar daripada bentuk sinyal parus pada duty cycle $75 \%$.

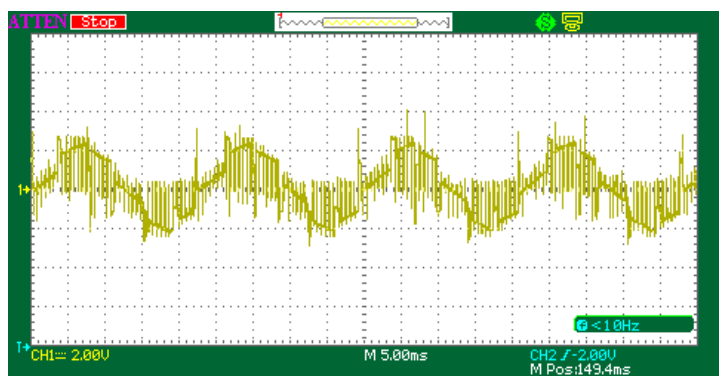

Gambar 19 gelombang tegangan tiap fasa Van tada duty cycle $75 \%$

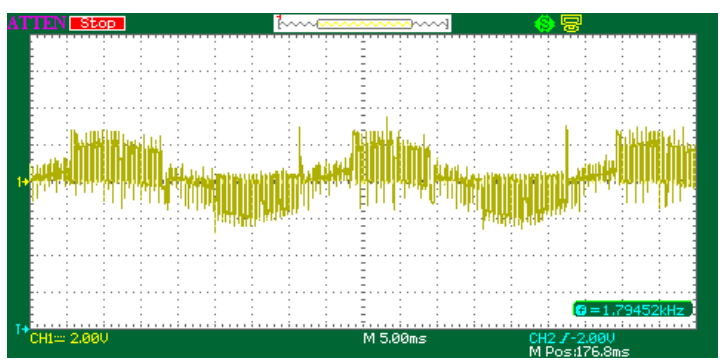

Gambar 20 gelombang tegangan tiap fasa Van pada duty cycle $50 \%$

Dapat dilihat pada gambar 19 dan gambar 20 bahwa perbandingan sinyal tegangan tiap fasa Van pada duty cylcle $50 \%$ bentuk sinyal arus lebih lebar daripada bentuk sinyal parus pada duty cycle $75 \%$

\section{Kesimpulan}

Pengaturan kecepatan motor BLDC secara variable dapat dilakukan dengan menggunakan kendali PWM. Kendali PWM secara tidak langsung adalah mengendalikan duty cyle yang akan berpengaruh pada tegangan yang terkena pada motor, ketika tegangan meningkat arus pada motor BLDC tersebut juga akan meningkat. Arus sebanding dengan torka pada motor sehingga torkanya juga akan meningkat.

\section{Nomenkaltur}

\begin{tabular}{|c|c|c|}
\hline ton & $=$ & $\begin{array}{l}\text { Waktu dimana tegangan } \\
\text { keluaran berada pada } \\
\text { posisi tinggi }\end{array}$ \\
\hline$t_{\text {off }}$ & $=$ & $\begin{array}{l}\text { Waktu dimana tegangan } \\
\text { keluaran berada pada } \\
\text { posisi rendah }\end{array}$ \\
\hline total & $=$ & Waktu satu siklus ( $\left.T_{\text {on }}+T_{\text {off }}\right)$ \\
\hline D & $=$ & Duty Cycle \\
\hline$V_{\text {out }}$ & $=$ & Tegangan keluaran (volt) \\
\hline$V_{\text {in }}$ & $=$ & Tegangan masukan (volt) \\
\hline
\end{tabular}




\section{Daftar Pustaka}

[1] Jian., Z, Yangwei, Y. AN047. Brushless DC Motor Fundamentals Application Note. Juli 2011

[2] Brown, Ward. Microchip Technology Inc. AN857. Brushless DC Motor Control Made Easy. 2012

[3] Gultom, Leothamrin. “Aplikasi Pembangkit PWM pada mikrokontroler ATMega 8535 Untuk mengendalikan Suhu Pemanas Air (Heater). 2011

[4] Samsul Arifin, Akhmad Fatoni "Pemanfaatan Pulse Width Modulation Untuk Mengontrol Motor (Studi Kasus Robot Otomatis Dua Deviana). Agustus 2014

[5] Agung Dwi Yulianta, Sasongko Pramono Hadi, Suharyanto "Pengendalian Kecepatan Motor Brushless DC (BLDC) menggunakan Metode Logika Fuzzy". Jurnal Sains,Teknologi dan industri Juni 2015

[6] Mahadian Dewangga, Bambang Sujanarko, Satryo Budi Utomo "Desain Sistem Kontrol Kecepatan Motor BLDC Berbasis Programmable Array Logic Dengan Metode Six Step Communitation". 2014

[7] Nanda Redha Arsya, Heri Suryoatmojo, Sjamsjul Anam "Desain Kontrol Kecepatan Motor Brushless DC Berbasis Power Factor Correction (PFC) Menggunakan Single Ended Primary Inductance Converter (SEPIC)". Jurnal TeknikITS. 2016

[8] Adnan Mohammad, Md. Anwarul Abedin, Md. Zianurrahman Khan. "Implementation Of a Three Phase Inverter For BLDC Motor Drive". 2016

[9] Ronaldi Hutabalian, Amir Hmazah. “Desai dan Analisa Inverter Tiga Fasa Dengan Metode SVPWM Sebagai Penggerak Motor Induksi Tiga Fasa Pada Aplikasi Sepeda Listrik. 2016

[10] Sutedjo, Ony Asrarul Qudsi, Suhariningsih. "Desain Dan Implementasi Six-step Comutation Pada Sistem Kontrol Motor BLDC 1,5 kW". 2017 